\title{
Jacques Dubois, Stendhal: une sociologie romanesque
}

\section{Annalisa Bottacin}

\section{(2) OpenEdition}

\section{Journals}

\section{Edizione digitale}

URL: http://journals.openedition.org/studifrancesi/8293

DOI: 10.4000/studifrancesi.8293

ISSN: 2421-5856

\section{Editore}

Rosenberg \& Sellier

\section{Edizione cartacea}

Data di pubblicazione: 1 mai 2009

Paginazione: 190

ISSN: 0039-2944

\section{Notizia bibliografica digitale}

Annalisa Bottacin, «Jacques Dubois, Stendhal: une sociologie romanesque», Studi Francesi [Online], 157 (LIII | I) | 2009, online dal 30 novembre 2015, consultato il 12 janvier 2021. URL: http://

journals.openedition.org/studifrancesi/8293 ; DOI: https://doi.org/10.4000/studifrancesi.8293

Questo documento è stato generato automaticamente il 12 janvier 2021.

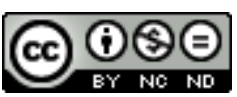

Studi Francesi è distribuita con Licenza Creative Commons Attribuzione - Non commerciale - Non opere derivate 4.0 Internazionale. 


\title{
Jacques Dubois, Stendhal: une sociologie romanesque
}

\author{
Annalisa Bottacin
}

\section{NOTIZIA}

JACQUES DUBOIS, Stendhal: une sociologie romanesque, Paris, La Découverte, 2007, pp. 252.

1 Il metodo più consueto per accostarsi al problema dei rapporti tra letteratura e società è lo studio dell'opera letteraria, vista quale documento sociale e quadro nitidissimo della realtà sociale, quanto si propone Jacques Dubois in quest'importante lavoro dedicato alla narrativa Sten-dhaliana, accostandosi alla cosa letteraria attraverso un'impostazione sociologica, che commisura le singole opere al processo storico-sociale che esse rispecchiano, esaminando quanto colgano la sostanza della stessa e sappiano rappresentarla attraverso le azioni dei personaggi e i loro comportamenti.

2 Come Dubois ribadisce nell'«avant-propos» (pp. 11-22), in parte confutando le asserzioni di una critica, che solo più tardi avrebbe proceduto verso il proprio rinnovamento, portata a vedere i personaggi Sten-dhaliani intimamente legati alla sfera dell'arrivismo e dell'ambizione, il romanzo Sten-dhalanio è piuttosto una ricerca di complicità con il sociale, scevro da ipocrisie e compromessi, quello che Dubois definisce «cercle primitif», traendo l'aggettivo "primitif» dalla Chartreuse de Parme. Sono infatti «primitifs» Octave de Malibert quanto Lamiel. «Tout cela veut que Stendhal se retrouve en romancier politique, le plus résolument politique peut-être de la littérature française», scrive Dubois (p. 29), e procede in modo pregnante evidenziando in un'analisi dettagliata e precisa che il compito proprio di Sten-dhal è quello di configurare adeguatamente la realtà del suo tempo, concentrando nella trasformazione sempre più marcata dei rapporti interpersonali e amorosi un sorprendente affresco di varie classi sociali che si affrontano, con posizioni sovente contraddittorie, simbolo di un'evidente evoluzione verso la modernità. L'articolazione della sua esegesi si dirama nella storia conflittuale dei personaggi, da vedersi quale presupposto in Sten-dhal 
dell'esercizio narrativo; in effetti, il volume di Dubois è diviso in undici capitoli, il cui criterio rimanda a un approfondito studio di personaggi e situazioni in un contesto storico ben delineato: «Le roman politique» (pp.23-39); «Le roman sociologue» (pp 40-60); «La montée des femmes» (pp. 61-75); «Armance sans voix» (pp. 76-91); «Des noirs et des rouges» (pp. 92-110); «Intense Louise, impétueuse Mathilde» (pp. 115-33); «Un héros du juste milieu» (pp. 134-155); «Entre Bathilde et Augustine» (pp. 156-169); «Des primitifs et des poudrés» (pp.170-91); «Insolente Gina, intransigeante Clélia» (pp. 195-217); «Lamiel sans fin» (pp. 218-37). Segue conclusione «Une sociologie romanesque» (pp.238-246), e una corposa e aggiornata "Bibliographie sélective d'ouvrages et articles sur Sten-dhal» (pp. 247-249). 